УДК: 621.01 DOI 10.36910/6775.24153966.2019.67.11

С.О. Кошель, Г.В. Кошель

Київський наиіональний університет технологій та дизайну

\title{
СТРУКТУРНИЙ АНАЛІЗ СКЛАДНИХ МЕХАНІЗМІВ ТРЕТЬОГО ТА ЧЕТВЕРТОГО КЛАСІВ
}

Розглянуто структурне дослідження складних плоских механізмів третього та четвертого класі зі степенем вільності $W=1$, щңо базуються на основі різних можлливих видів структурних групи третього та четвертого класу, які ураховують кількість і певний характер кінематичних пар та їх місце розташування в групі. Структурний аналіз зроблено за допомогою способу умовної зміни ведучої ланки механізму, який дозволяє отримати формули будов кінематично-еквівалентних механізмів другого або третього класів, щцо дозволяє з'ясувати послідовність визначення кінематичних параметрів точок та ланок механізмів відповідного класу, спростити кінематичний аналіз та збільиити точність результатів дослідження.

Ключові слова: структурна група, механізм, структурна формула, ланка.

\section{С.О. Кошель, А.В. Кошель \\ СТРУКТУРНЫЙ АНАЛИЗ СЛОЖНЫХ МЕХАНИЗМОВ ТРЕТЬЕГО И ЧЕТВЁРТОГО КЛАССОВ}

\begin{abstract}
Рассмотрено структурное исследование сложных плоских механизмов третьего и четвертого классов со степенью свободы $W=1$, базирующиеся на основе различных видов структурных групп третьего и четвертого классов, которые учитывают количество и определенный характер кинематических пар и их местоположение в группе. Структурный анализ сделан с помощью способа условной замены ведущего звена механизма, который позволяет получить формулы строений кинематически-эквивалентных механизмов второго или третьего классов, позволяет выяснить последовательность определения кинематических параметров точек и звеньев механизмов соответствующего класса, упростить кинематический анализ и увеличить точность результатов исследования .
\end{abstract}

Ключевые слова: структурная группа, механизм, структурная формула, звено.

\section{S. Koshel, A. Koshel \\ STRUCTURAL ANALYSIS OF THE COMPLEX MECHANISMS OF THE THIRD AND FOURTH CLASSES}

A structural study of complex plane mechanisms of the third and fourth classes with a degree of freedom $W=1$, based on various possible types of structural groups of the third and fourth classes, which take into account the number and specific nature of kinematic pairs and their location in the group Structural analysis is made by a method of conditional change of the leading link of the mechanism, which allows to obtain formulas of structures of kinematically equivalent mechanisms of the second or third classes, which allows to find out the sequence of determination of kinematic parameters of points and links of mechanisms of the corresponding class, to simplify the kinematic analysis and to increase the accuracy of the results of the study..

Keywords: structural group, mechanism, structural formula, link.

\section{Постановка проблеми.}

Вдосконалення існуючого технологічного обладнання легкої промисловості та проектування нових машин пов'язано 3 досконалістю методів аналізу структурних груп ланок плоских механізмів, з яких останні складаються. Найбільш розробленими є методи дослідження груп, до складу яких надходять дві ланки та три кінематичні пари. Знайдені та достатньо відомі традиційні методи аналізу структурних груп 3 чотирма ланками та шістьма кінематичними парами, що утворюють групи третього класу, на основі яких можна структурно синтезувати механізми відповідного класу.

Структурні групи вищого класу, до складу яких надходять чотири, шість або більше ланок 3 відповідною кількістю кінематичних пар 3 одного боку вже використовуються або мають перспективи до застосування в механізмах технологічного обладнання легкої промисловості, 3 іншого - не мають розроблених універсальних методів кінематичного та динамічного досліджень. Пов’язано таке з різноманіттям видів структурних груп, які можуть бути утворені чотирма, а в особливості шістьма та більшою кількістю ланок та відповідними їм кінематичними парами.

Недостатня розробка способів структурного аналізу таких груп є фактором стримування їх використання в технологічному обладнанні машинобудівельних галузей виробництв, зокрема, в машинобудуванні легкої промисловості, тому дослідження, які пов’язані з структурним аналізом складних плоских механізмів є актуальними в сучасних умовах розвитку теорії будови механізмів.

Аналіз останніх досліджень і публікацій. Питанням практичного використання та теоретичного дослідження структурних, кінематичних та динамічних параметрів плоских 
складних механізмів вищих класів присвячена значна кількість публікацій останніх років. Так патентами на корисну модель $[1,2,3]$ захищено право використання систем багатоланкових структурних груп ланок в певних механізмах практичного характеру застосування. Питанням теоретичного дослідження механізмів вищого класу присвячується ряд робіт, в яких розглядаються задачі структурно-оптимізаційного синтезу складного механізму 3 можливим вистоюванням веденої ланки [4], кінематичного та силового аналізу складної структурної групи ланок, що утворюють замкнений контур зі змінними геометричними параметрами [5], задач теоретичного аналізу механізму шостого класу $[6,7]$, зокрема механізмів обладнання легкої промисловості $[8,9]$.

Постановка завдань. Метою роботи $є$ структурне дослідження механізмів третього та четвертого класів різних варіантів, що складаються з структурних груп, до складу яких надходить чотири ланки та шість кінематичних пар, яке б дозволило отримати структурні формули будов складних плоских механізмів, що досліджуються з урахуванням властивостей структурних схем змінювати клас механізму в залежності від обраної іншої можливої вхідної ланки механізму.

Дослідженню підлягають структурно можливі механізми третього та четвертого класів різних видів на основі структурних груп ланок третього класу третього порядку та четвертого класу другого порядку.

Отримані результати у вигляді формул будов механізмів дозволять по-перше розробити послідовність дій для подальшого кінематичного дослідження параметрів точок, що співпадають 3 геометричними центрами кінематичних пар структурних груп механізмів, а по-друге - спростити такі дослідження в зв'язку 3 можливістю визначення оптимального варіанту початкового механізму в формулі будови механізму, для якого клас механізму, що досліджується набуває найменшої можливої величини.

Викладення основного матеріалу. Розглянемо різні модифікації структурних груп третього (рис. 1) та четвертого класів (рис. 2), що складаються 3 чотирьох ланок (2 - 5) та 3 шести кінематичних пар п’ятого класу.

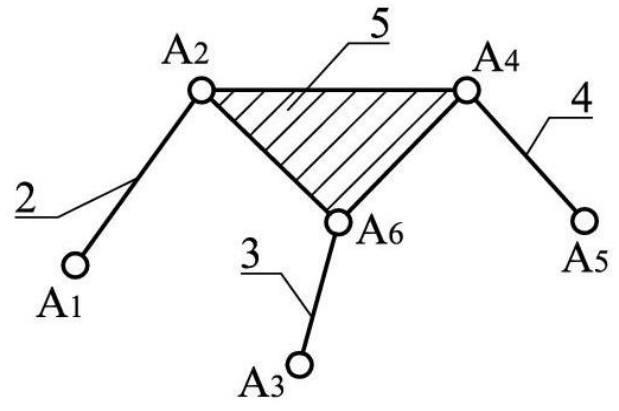

Рис. 1. Структурна група третього класу 3 шістьма обертальними парами

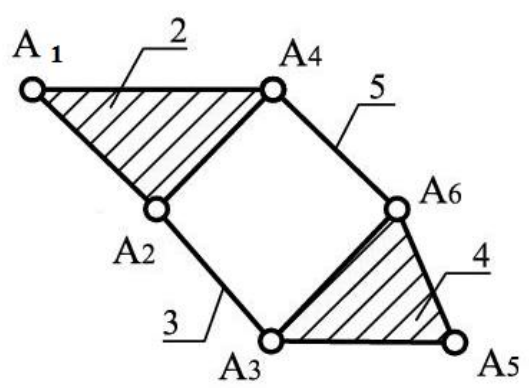

Puc. 2. Структурна група четвертого класу 3 шістьма обертальними парами

Для групи третього класу маємо такі варіанти структурних груп:

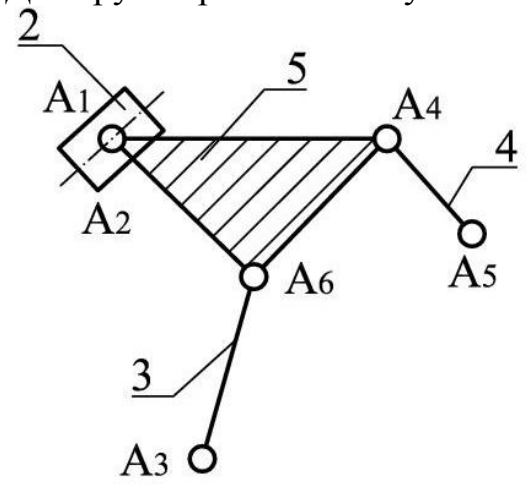

Рuc. 1.1. Структурна група третього класу 3 однісю поступальною парою

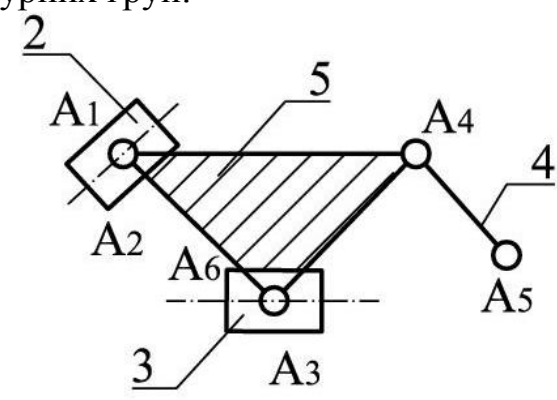

Рuc. 1.2. Структурна група третього класу 3 двома поступальними парами 

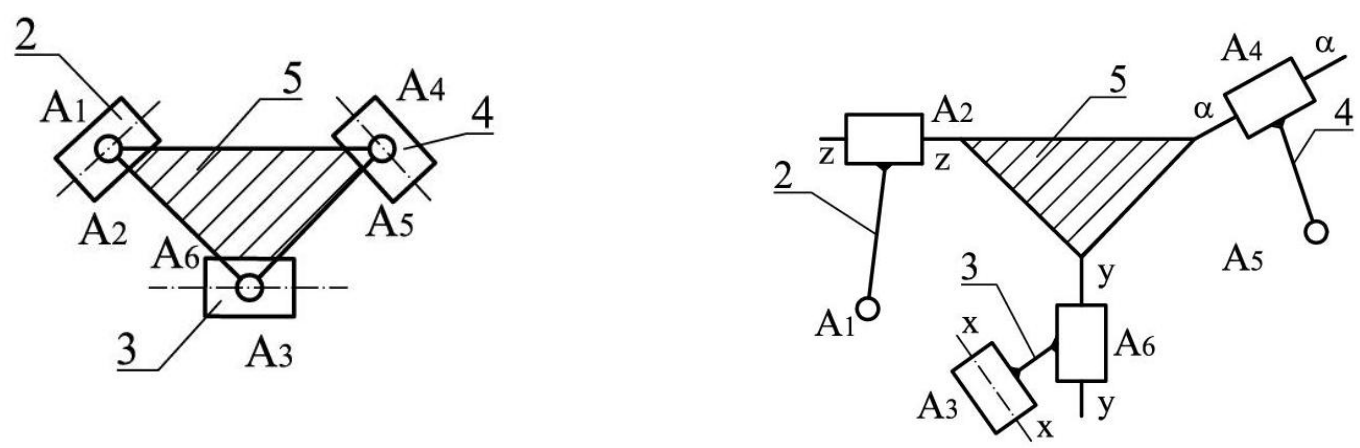

Рuc. 1.3. Структурна група третього класу 3 трьома поступальними парами

Рuc. 1.4. Структурна група третього класу 3

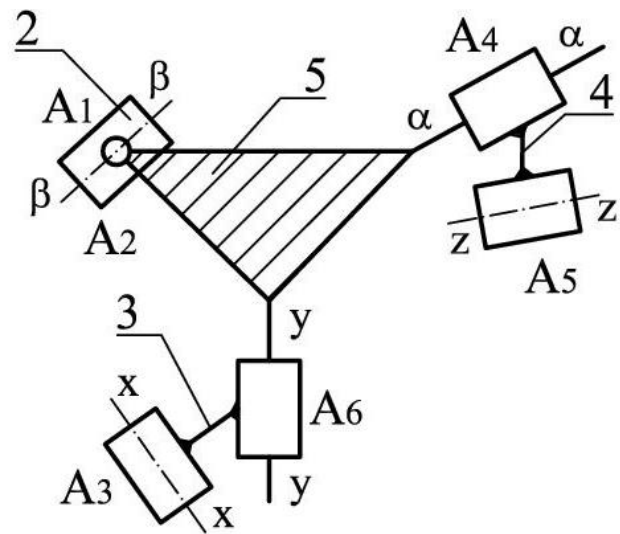
чотирма поступальними парами

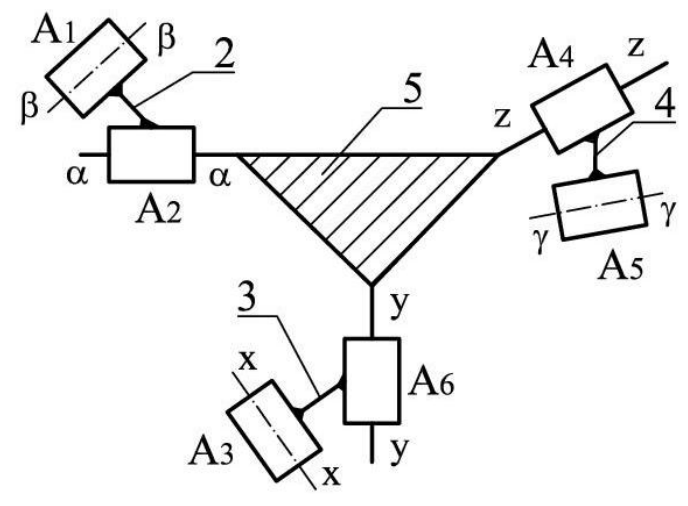

Рuc. 1.5. Структурна група третього класу з п'ятьма поступальними парами

Puc. 1.6. Структурна група третього класу 3 шістьма поступальними парами

Для групи четвертого класу маємо такі варіанти структурних груп:

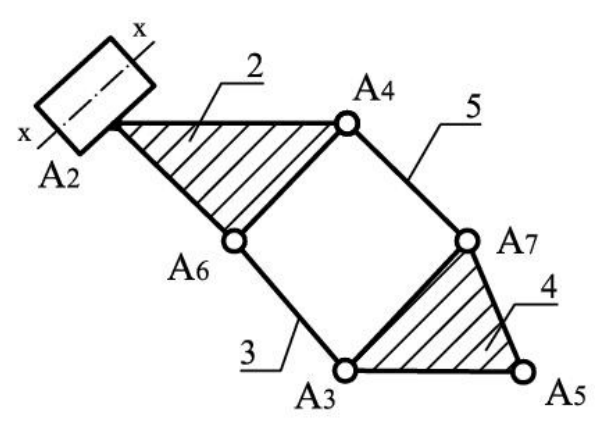

Рuc. 2.1. Структурна група четвертого класу з однією поступальною парою

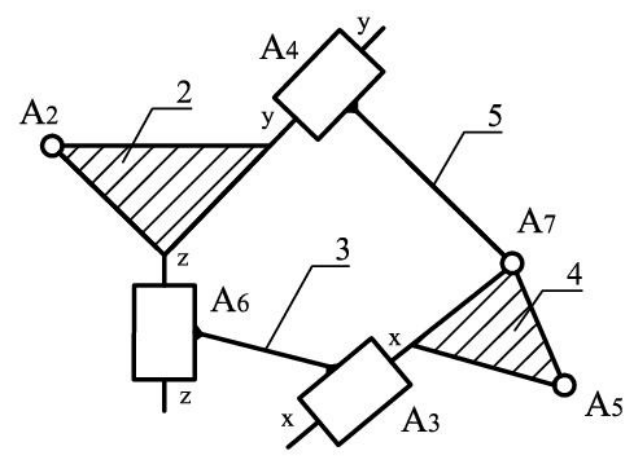

Рuc. 2.3. Структурна група четвертого класу з трьома поступальними парами

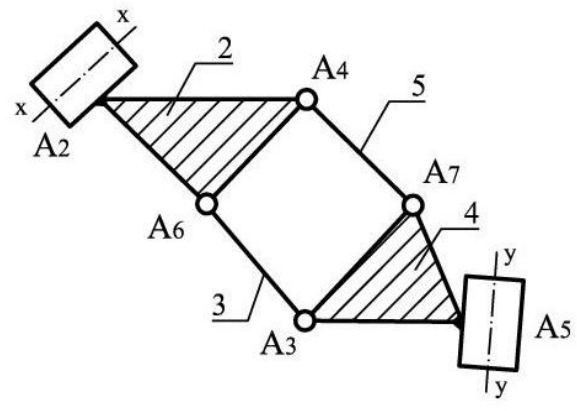

Рuc. 2.2. Структурна група четвертого класу 3 двома поступальними парами

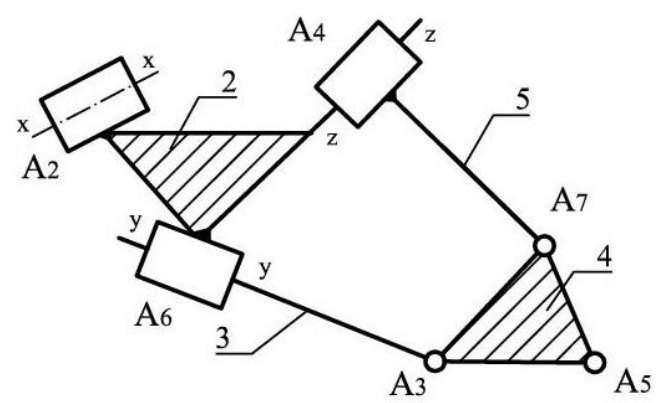

Рuc. 2.4. Структурна група четвертого класу 3 трьома поступальними парами 


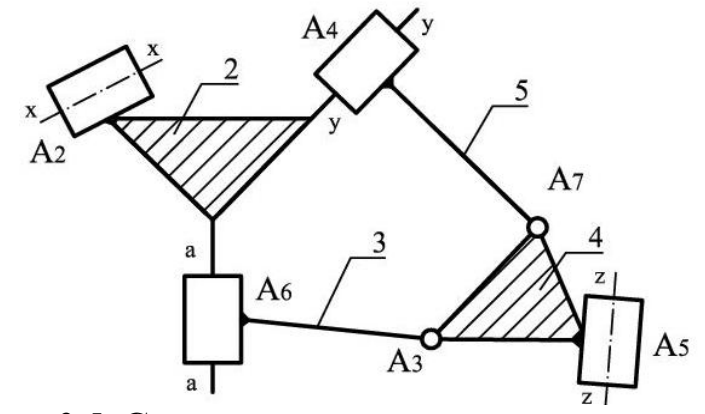

Рuc. 2.5. Структурна група четвертого класу 3 чотирма поступальними парами

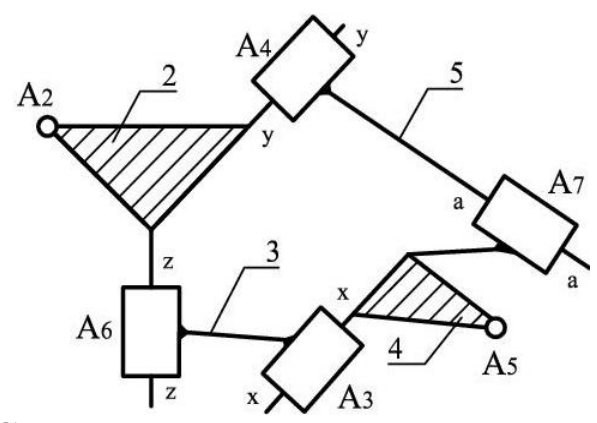

Рис. 2.7. Структурна група четвертого класу з чотирма поступальними парами

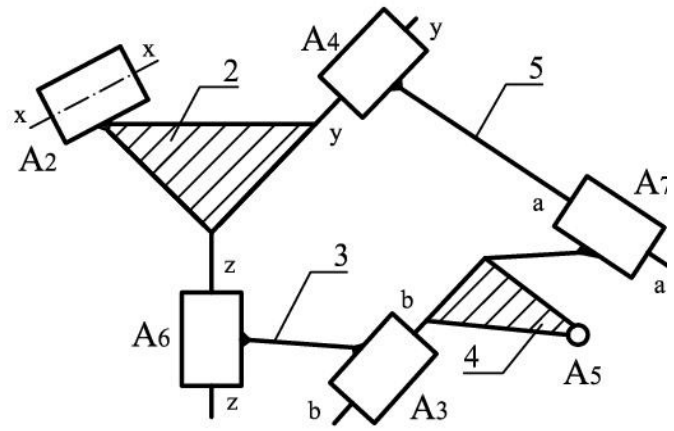

Рис. 2.9. Структурна група четвертого класу 3 п'ятьма поступальними парами

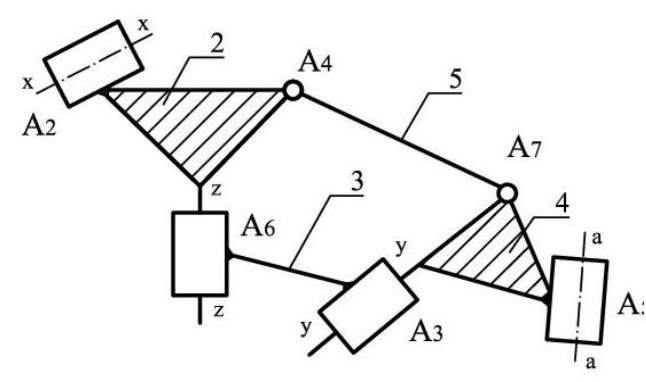

Рuc. 2.6. Структурна група четвертого класу 3 чотирма поступальними парами

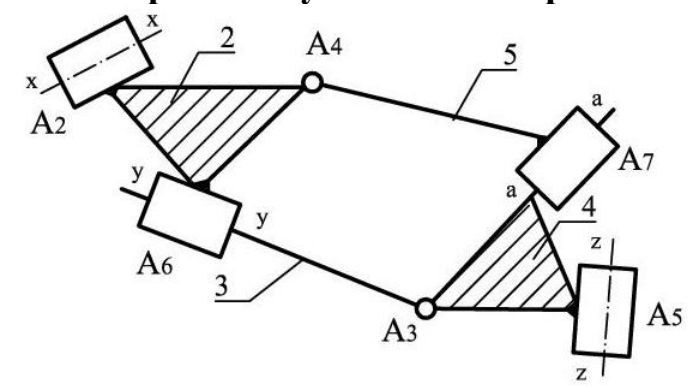

Рuc. 2.8. Структурна група четвертого класу 3 чотирма поступальними парами

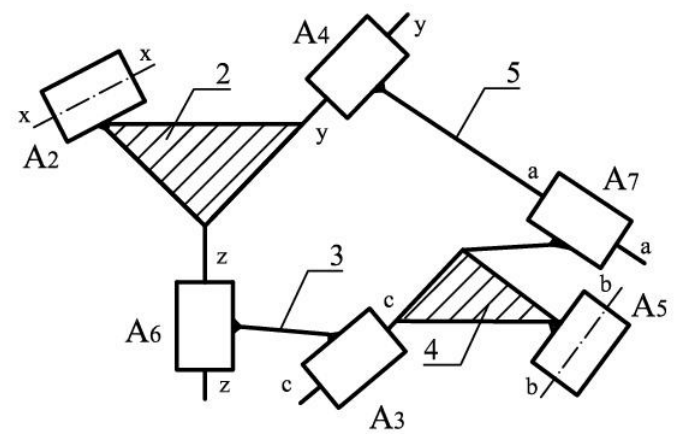

Рис. 2.10. Структурна група четвертого класу з шістьма поступальними парами

Для визначення послідовності дослідження механізмів на основі наведених варіантів структурних груп третього класу (рис. 1.1 - 1.6) згідно з умовною зміною ведучої ланки будемо вважати, що дійсна ведуча ланка 1 механізму (кривошип) утворює 3 ланкою 2 групи кінематичну пару $\mathrm{A}_{1}$, а дві інші зовнішні кінематичні пари $\mathrm{A}_{3}, \mathrm{~A}_{5}$ утворені відповідними ланками 3,4 структурної групи та стояком 0. Якщо для механізмів на основі наведених структурних груп вважати умовно іншою ведучою ланкою кривошип 4, формули будов механізмів, що $\epsilon$ кінематично-еквівалентними механізмам третього класу набувають вигляду:

\footnotetext{
1клас $\rightarrow 2$ клас 2порядок 1вид $\rightarrow$ 2клас 2порядок 3 вид - структурна схема рис 1.1;

(лланк 0,4$) \quad$ (лланк 3,5$) \quad$ (лланк 1,2$)$

1клас $\rightarrow 2$ клас 2порядок 2вид $\rightarrow$ 2клас 2порядок 3 Вид - структурна схема рис 1.2;

(лланк 0,4$) \quad$ (лланк 3,5$) \quad$ (лланк 1,2$)$

1клас $\rightarrow$ 2клас 2порядок 2вид $\rightarrow$ 2клас 2порядок 3 вид - структурна схема рис 1.3;

(лланк 0,4$) \quad$ (лланк 3,5$) \quad$ (лланк 1,2$)$

1клас $\rightarrow 2$ клас 2 2порядок 6 вид $\rightarrow 2$ клас 2 2порядок 2 2вид - структурна схема рис 1.4 ;

(лланк 0,4$) \quad$ (лланк 3,5$) \quad$ (лланк 1,2$)$
} 


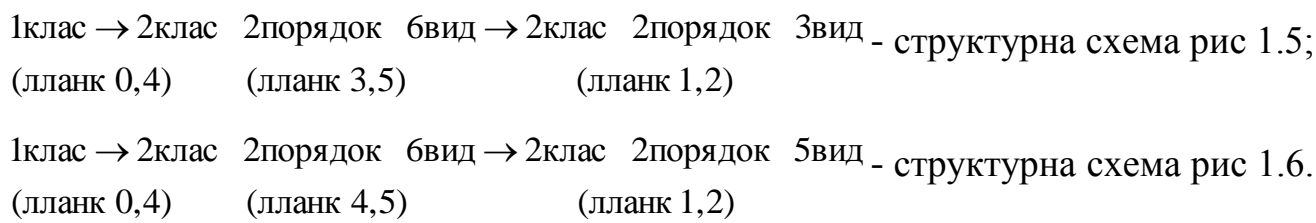

Для визначення послідовності дослідження механізмів на основі наведених варіантів структурних груп четвертого класу (рис. 2.1 - 2.10) згідно з умовною зміною ведучої ланки будемо вважати, що дійсна ведуча ланка 1 механізму (кривошип) утворює 3 ланкою 2 групи кінематичну пару $\mathrm{A}_{2}$, а інша зовнішня кінематичні пари $\mathrm{A}_{5}$ утворена ланкою 4 структурної групи та стояком 0. Якщо для механізмів на основі наведених структурних груп вважати умовно іншою ведучою ланкою кривошип 4, формули будов механізмів, що $є$ кінематично-еквівалентними механізмам четвертого класу набувають вигляду:

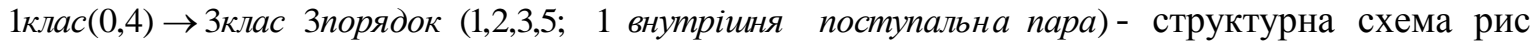
2.1;

$1 \kappa л а с ~(0,4) \rightarrow 3$ клас Зпорядок $(1,2,3,5 ; 1$ внутрішня поступальна пара) - структурна схема рис 2.2;

$1 \kappa л а с(0,4) \rightarrow 3$ злас Зпорядок (1,2,3,5; 1 зовнішня , 2 внутрішні поступальні пари $)$

- структурна схема рис 2.3 ;

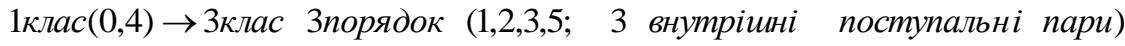

- структурна схема рис 2.4;

1 клас $(0,4) \rightarrow 3$ клас Зпорядок $(1,2,3,5 ; 3$ внутрішні поступальні пари $)$

- структурна схема рис 2.5 ;



- структурна схема рис 2.6 ;

$1 \kappa л а с ~(0,4) \rightarrow 3$ злас Зпорядок $(1,2,3,5 ; 2$ зовнішні , 2 внутрішні поступальні пари $)$

- структурна схема рис 2.7 ;

1 клас $(0,4) \rightarrow 3$ клас Зпорядок $(1,2,3,5 ; 1$ зовнішня , 2 внутрішні поступальні пари $)$

- структурна схема рис 2.8 ;

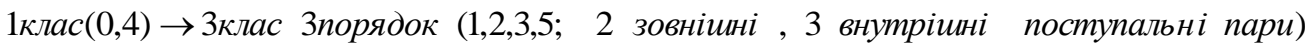

- структурна схема рис 2.9 ;

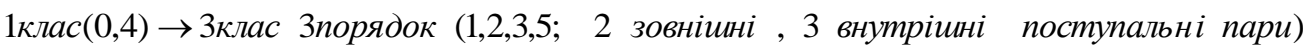

- структурна схема рис 2.10 .

Аналіз отриманих формул будов механізмів третього та четвертого класів різних видів на основі структурних груп ланок третього класу третього порядку та четвертого класу другого порядку дозволяє стверджувати, що механізми третього класу можна дослідити в послідовності, яка обумовлена кінематично-еквівалентними механізмами другого класу, а механізми четвертого класу - механізмами третього класу.

Висновки. Зроблено структурне дослідження механізмів третього та четвертого класів на основі можливих варіантів структурних груп третього класу третього порядку та четвертого класу другого порядку за допомогою умовної зміни ведучої ланки механізму. Отримані результати дозволяють спростити кінематичний аналіз таких механізмів та збільшити точність результатів дослідження. 


\section{Список використаних джерел:}

1. Патент РФ 2201348 Кривошипно-ползунный механизм пресса, авторы Дворников Л.Т., Чужиков О.С., Стариков С.П., 27.03.2003 г.

2. Патент РФ 2303699 Секция механизированной крепи, авторы Дворников Л.Т., Князев А.С., Стариков С.П., 27.07.2007 г.

3. Патент РФ 2332260 Двухщековая дробильная машина, авторы Дворников Л.Т., Стариков С.П., 27.08.2008 г.

4. Кикин А.Б. Аналитико-оптимизационный синтез шестизвенного механизма с выстоем / А.Б. Кикин, Э.Е. Пейсах// Известия высших учебных заведений. Технология текстильной промышленности. - 2008. - № 5. - С. 79-83.

5. Дворников Л.Т. Исследование кинематики и кинетостатики плоской шарнирной шестизвенной группы Ассура с четырехугольным замкнутым изменяемым контуром/ Л.Т. Дворников, С.П. Стариков // Известия ВУЗов, «Машиностроение». - 2008. - №4. - С. 3 - 10.

6. Чашников Д.О. Кинематическое исследование плоского восьмизвенного механизма шестого класса с поступательной парой / Д.О. Чашников, В.В. Гаряшин // Успехи современного естествознания. - 2011. №7. - С. $231-232$.

7. Чашников Д.О. Кинематическое исследование плоского восьмизвенного механизма шестого класса с поступательной парой аналитическим методом / Д.О. Чашников, В.В. Гаряшин // Успехи современного естествознания. - 2012. - №6. - С. 158 - 159.

8. Гебель Е. С. Моделирование кинематики механизма игл основовязальной машины / Е. С. Гебель, Е. В. Солонин // Сборник материалов X междунар. научно-практ. конф. «Теоретические знания в практические дела»: в 2 ч. - Омск.: Филиал ГОУ ВПО «РосЗИТЛП» в г. Омске, - 2009. Ч. 2. - С. 211 - 215.

9. Кикин А.Б. Синтез рычажных механизмов для привода нитераскладчика мотальной машины / А.Б. Кикин // Известия высших учебных заведений. Технология текстильной промышленности. - 2005. - № 1. C. $115-119$.

\section{Рецензенти:}

Місяць Володимир Петрович, професор кафедри Прикладної механіки та машин Київського національного університету технологій та дизайну, доктор технічних наук, професор

Защепкіна Наталія Миколаївна, в.о. завідувача кафедри наукових, аналітичних та екологічних приладів і систем Національного технічного університету України «Київський політехнічний інститут імені Ігоря Сікорського», доктор технічних наук, професор. 